\title{
Oasis or mirage? The safety of outpatient dental anaesthesia in hospital
}

From 1 January 2002, a healthy child in the UK who requires the simplest of dental extractions under general anaesthesia will have to be treated in a hospital with ready access to intensive care. However, an adult with significant concomitant disease will still be able to undergo total hip replacement, laparotomy or any number of other major surgical procedures in a medical facility without such resources. That this anomalous situation has arisen at all provides an interesting example of how even individuals trained in scientific method may be incapable of separating emotion and evidence.

Out-patient or 'chair dental' anaesthesia has always had the capacity to polarize opinion amongst anaesthetists, between those who believe it to be barbarous and lethal, and others - mainly its practitioners - who believe it to be a high art form. Yet the evolution of anaesthesia itself does have its humble origins in dentistry, with the first authenticated general anaesthetic in England taking place in London in 1846, with the use of ether for dental extraction. In the UK, if not elsewhere, a longstanding cultural acceptance has characterized this form of anaesthesia, particularly in areas of socio-economic deprivation with high rates of dental caries, so that even $150 \mathrm{yr}$ later, inhalational anaesthesia for simple exodontia still takes place. The reasons are not hard to find: the pain of toothache is severe, universal, and cured easily by extraction. That was true in 1846 and it is true today, which is why during any year in the 1950 s there were upwards of 3.5 million dental anaesthetics given in the UK. Many combining influences have ensured that numbers have declined steadily from that peak, but even during the 1990s, there were still over 300000 cases performed annually. One such influence was the perception that chair dental anaesthesia is uniquely dangerous, and indeed it was a cluster of fatalities in children in the late 1990s in the UK that precipitated a dramatic change in the regulations.

Correspondence to: Simon Bricker, Department of Anaesthesiology, The Countess of Chester Hospital, Chester, CH2 1UL, UK. E-mail: bricker@ globalnet.co.uk; Tel: +44 (0)1244 365461; Fax: +44(0)1244 365435

Accepted for publication September 2001 EJA 1022
What is the evidence on which this perception is based? In respect of all hospital anaesthetics, the early landmark report of Lunn and Mushin in 1982 [1] produced pessimistic figures of one death per 10000 anaesthetics. However, the first Report of the Confidential Enquiry into Perioperative Deaths (CEPOD) by Buck and colleagues in 1987 [2] quoted mortality rates solely associated with anaesthesia at a more realistic 1:185000 administrations. Coplans and Curson examined deaths associated specifically with dental anaesthesia over $20 \mathrm{yr}$ from 1970 to 1989 in studies that identified 54 deaths in the first decade and 18 in the second [3,4]. There were 119 fatalities overall, $60 \%$ of which occurred outside hospital and $29 \%$ of which involved children. In the first decade, denominator data allowed these authors to establish a mortality rate of $1: 230000$. Total general anaesthetic numbers were not available for the second decade, but best estimates suggest that the mortality rate was equally low. Meanwhile, figures issued by the UK Department of Health $(\mathrm{DoH})$ show that over the past $30 \mathrm{yr}$ there have been 147 deaths with a child-to-adult ratio of $1: 2$ [5]. Despite the alleged perils of chair dental anaesthesia, therefore, it would seem that these statistics confirm that there is no safer form of general anaesthesia. Other investigators had also looked at dental anaesthetic deaths, with Tomlin in 1974 [6] quoting an even lower mortality rate of $1: 274000$, in spite of anaesthetic practices such as this: 'Anaesthesia was induced with $100 \% \quad \mathrm{~N}_{2} \mathrm{O}$ which was gradually reduced to $90 \%$ and then to $80 \%$ while unknown concentrations of halothane and trichloroethylene were administered.' This adult suffered a fatal cardiac arrest, which is perhaps no great surprise, yet it is certainly possible that such techniques were widespread. What may have protected most patients from disaster is that out-patient dental anaesthesia typically has always been very swift. In one series of 12000 cases, the mean time from the start of induction until eye opening on command was $251 \mathrm{~s}$ in children and $307 \mathrm{~s}$ in adults (S. R. W. Bricker, personal data), which confirms the transient nature of this form of anaesthesia. It is likely that this brevity has 
contributed to safety statistics and perhaps has allowed anaesthetists to use disreputable techniques without causing the carnage that might otherwise ensue were procedures to be prolonged. It is also probable that because most children are inherently fit and healthy, mortality rates have remained low. But mortality rates have remained finite and so have continued to be the subject of fitful concern, precipitating during the 1990s a series of official reports that aimed both to raise the standards of out-patient dental anaesthesia and to reduce the overall numbers administered. The first of these was by Poswillo in 1990 [7], which was followed in turn by the Clinical Standards Advisory Group Report by Seel in 1995 [8], the General Dental Council (GDC) Recommendations to Practitioners in 1998 [9] and the report by the Royal College of Anaesthetists on dental anaesthesia in 1999 [10]. The revised GDC regulations in particular had a marked effect, and in the first quarter following the announcement, overall numbers fell by $80 \%$ [5]. However, DoH figures confirmed that there continued to be fatalities, some of which received substantial media attention, and it was in this context that the Chief Medical and Dental Officers of England and Wales produced their report on dental anaesthesia in primary care [5]. It is, on balance, an unimpressive document. In response, it would seem - to tabloid frenzy over the tragic deaths of a small number of children - the report has created a standard for dental anaesthesia that far exceeds that for every other surgical specialty. Take, for example, the role of the dentist on whom has been imposed vicarious liability, and who has responsibility for the clinical standards within the unit to which a patient may be referred: 'Referring dentists have a responsibility to ascertain that the facilities at the premises to which they refer patients are adequate and that clinical staff are properly trained.' Were this extraordinary requirement to be applied equally to general medical practitioners it would, quite rightly, be derided as unworkable and unfair.

What of the central issue of venue? The report states that 'dental treatment under general anaesthesia should be provided in a hospital setting'. 'Hospital setting' was defined carefully as 'any institution for the reception and treatment of persons ... requiring medical or dental treatment, ... has critical care facilities on the same site ... and includes clinics and outpatient departments maintained in connection with any such institution'. It was clear that this was defining in effect a typical acute hospital. As far as the term 'critical care facilities' was concerned, most UK anaesthetists assumed that this meant what it had always meant: namely, an intensive care unit (ICU) or at the very least a high-dependency unit (HDU). This is not so. In supplementary guidance issued by the DoH in May 2001 [11], it was stressed that critical care facilities are not necessarily dedicated HDUs or ICUs, but are areas in which the necessary resuscitative expertise can be marshalled pending expeditious transfer. Such expertise includes 'additional skilled support', which means, presumably, a cardiac arrest team. The DoH had clearly realized the illogicality of its original recommendations, but was limited in how far it could mangle the meaning of the language without creating loopholes that would have negated its primary intentions.

The central recommendations of this Report lack common sense and have no basis in objective evidence, yet what appears to underlie them is the attitude that dental treatment somehow is not deserving of general anaesthesia. The fact that no central funding whatever has been provided to facilitate the move of community dental services into hospital is evidence enough for this contention. The Report stresses that 'given the risk associated with the procedure general anaesthesia should be undertaken only when absolutely necessary'. Many anaesthetists might well agree, conversant as most are with data from diverse areas of clinical practice that confirm that local or regional anaesthesia is safer than general anaesthesia. Logic dictates, therefore, that there should be equal clamour from the Chief Medical Officer and others to convert all these unnecessary general anaesthetics in surgical practice to local anaesthesia. Such clamour is not apparent.

What these recommendations have also missed is the crucial fact that the various enquiry reports into the recent deaths of children undergoing dental anaesthesia have confirmed that by far the most important contributory factor to these tragedies was not the venue but the incompetence of the anaesthetists involved [12,13].

But have we ended up with the correct solution for the wrong reasons? There is no evidence to support the absolute necessity for a hospital-based service, and the new regulations were precipitated as much by emotion as by reason. Yet, who does not feel intuitively that somehow it is better and safer for children to be anaesthetized within an acute hospital? We should beware of that assumption. Davies and Nind [14] surveyed European practice in a number of different countries via a questionnaire relating to the management of sample clinical situations. Their worst-case scenario was a child requiring extraction of four deciduous molars plus three other teeth. In some European countries, this mandates hospital referral for anaesthesia with tracheal intubation. This technique surely is excessively complex, given that the anaesthetic and extraction time 
for this combination of teeth is less than $300 \mathrm{~s}$ (Bricker, unpublished data). In one small study from Leeds, no fewer than $4 \%$ of children who were anaesthetized with a laryngeal mask technique in hospital required emergency tracheal intubation. None of the children anaesthetized using the traditional nasal mask technique needed such intervention [15]. Moreover, it should not be forgotten that $40 \%$ of deaths associated with dental anaesthesia in the last three decades have occurred within hospitals.

Another potentially dangerous assumption that underlies this Report is the belief that sedation is safer than general anaesthesia. That may be true certainly of 'conscious sedation', which, as it happens, is by no means easy to achieve in children, but emphatically it is not true of other forms of sedation. Department of Health figures confirm that since the GDC guidelines were introduced, there has been a national increase of $50 \%$ in sedation cases for dentistry [5]. Given the fact that in 2001 an anaesthetist in the UK was convicted of manslaughter after giving a combination of sedative drugs without basic monitoring and without possessing adequate skills in resuscitation, it is vital to ensure that sedation for dentistry receives the same robust scrutiny afforded to general anaesthesia.

Yet, despite the paucity of evidence, it seems evident that most anaesthetists accept that for outpatient dental anaesthesia, a well-organized and properly funded service on an acute hospital site may prove the most desirable option. However, when this finally comes to pass, we must guard against two significant dangers. Hospital-based practice must not put patients at risk with the unnecessary deployment of more complex and more hazardous anaesthetic techniques, and an exaggerated view of the purported risks of general anaesthesia must not encourage the widespread use of inappropriate sedation techniques which have their own very real potential for harm.

Simon Bricker

Department of Anaesthesia

The Countess of Chester Hospital

Chester, UK

\section{References}

1. Lunn JN, Mushin WW. Mortality Associated with Anaesthesia. London, UK: Nuffield Provincial Hospitals Trust, 1982.

2. Buck N, Devlin HB, Lunn JN. Report of the Confidential Enquiry into Perioperative Deaths. London, UK: Nuffield Provincial Hospitals Trust and The King Edward's Hospital Fund for London, 1987.

3. Coplans MP, Curson I. Deaths associated with dentistry 1970-1979. Br Dental J 1982; 153: 357-362.

4. Coplans MP, Curson I. Deaths associated with dentistry and dental disease 1980-1989. Anaesthesia 1993; 48: 435-438.

5. Donaldson L, Wild R. A Conscious Decision: A Review of the Use of General Anaesthesia and Conscious Sedation in Primary Dental Care. Report of a Group Chaired by the Chief Medical and Dental Officers. London, UK: Department of Health, 2000.

6. Tomlin PJ. Death in outpatient dental anaesthetic practice. Anaesthesia 1974; 29: 551-570.

7. Poswillo D. General Anaesthesia, Sedation and Resuscitation in Dentistry. Report of an Expert Working Party for the Standing Dental Advisory Committee. London, UK: Department of Health, 1990.

8. Seel D. Dental General Anaesthesia. Report of the Clinical Standards Advisory Group Committee on General Anaesthesia in Dentistry. London, UK: Faculty of Dental Surgery, Royal College of Surgeons of England, 1995.

9. General Dental Council. Maintaining Standards: Guidance to Dentists on Professional and Personal Conduct. London, UK: GDC, 1998.

10. Standards and Guidelines for General Anaesthesia for Dentistry. London, UK: Royal College of Anaesthetists, 1999.

11. Guidance Letter. General Anaesthesia for Dental Treatment in a Hospital Setting with Critical Care Facilities. London, UK: Department of Health, 2001.

12. Report of the Internal Inquiry into the Death of Katie Dougal. Derby, UK: Southern Derbyshire Health Authority, 1996.

13. Fatal Accident Inquiry. Inquiry into the Circumstances of the Death of Darren Denbolm. Edinburgh, UK: Sheriffdom of Lothian and Borders at Edinburgh, 2000.

14. Davies MW, Nind D. Anaesthesia for exodontia in young children - a snapshot survey of European practice. Anaesthesia 1996; 51: 713.

15. Slaymaker AE, Quinn AC, Edmondson RSE, et al. Comparing traditional chair dental anaesthesia with the laryngeal mask for simple exodontia in children. Proceedings of the Association of Dental Anaesthetists 1998; 16: 6-13. 